\title{
Carbon monoxide fermentation to bioplastic: the effect of substrate adaptation on Rhodospirillum rubrum
}

\author{
Beatrice Mongili $^{1} \cdot$ Debora Fino $^{1}$
}

Received: 15 April 2020 / Revised: 17 June 2020 / Accepted: 8 July 2020 / Published online: 18 July 2020

(C) The Author(s) 2020

\begin{abstract}
Rhodospirillum rubrum is a gram-negative bacterium that naturally takes advantage of $\mathrm{CO}$ and which, in the presence of acetate, accumulates carbon and energy units as polyhydroxybutyrate (PHB). Since the conversion of CO depends on a large protein membrane complex that is expressed after the exposure to carbon monoxide, this study presents the effects of a CO-based acclimation in R. rubrum on the growth trend and on the production of PHB. The strain was cultured in two consecutive fermentation cycles on $15 \%$ of $\mathrm{CO}$, and the behaviour of this species, in the presence of acetate or a reducing sugar, such as fructose, was compared. The exposure of R. rubrum to CO during the first adaptation phase led to the development of a metabolically active population characterised by a greater biomass growth. The supply of fructose ensured a shorter lag-phase and a higher biomass titre, but it also determined a decrease in the biopolymer accumulation. However, $R$. rubrum showed the best carbon utilisation in the absence of fructose, with a growth molar yield of $48 \mathrm{mg} \mathrm{mol}^{-1}$, compared to the $12 \mathrm{mg} \mathrm{mol}^{-1}$ obtained for fructose feeding.
\end{abstract}

Keywords PHB $\cdot$ Gas fermentation $\cdot$ Rhodospirillum rubrum $\cdot$ CO conversion $\cdot$ Adaptation

\section{Introduction}

The next few decades will be characterised by a radical change in the economy, which will evolve from the current linear type to the new concept of circular economy. This change in perspective requires a substantial evolution of the supply chain network, in which by-products should be designed to take part in new production cycles as secondary raw materials. Carbon monoxide is a harmful molecule for most living beings and a greenhouse gas that affects climate change. In this scenario, anthropogenic activities play a crucial role, contributing by around $70 \%$ to the global $\mathrm{CO}$ emissions in the atmosphere [1]. However, carbon monoxide can be used for a broad spectrum of applications in the microbial fermentation field, where it can be fed as a carbon source for all those microorganisms that can take advantage of it. Furthermore, even though this

Beatrice Mongili

beatrice.mongili@polito.it

Debora Fino

debora.fino@polito.it

1 Department of Applied Science Technology (DISAT), Politecnico di Torino, Corso Duca degli Abruzzi 24, 10129 Turin, Italy kind of technology has already been launched at an industrial scale, there is still a wide margin for improvement $[2,3]$.

The current environmental issues evidence the urgent need to substitute conventional fossil-based plastics materials with biodegradable polymers originating from renewable feedstock $[4,5]$. Polyhydroxybutyrate (PHB) is a biodegradable and biocompostable thermoplastic that is naturally synthesised, by several microbial species, as a carbon store and energy source for famine periods [6,7]. One of these species is Rhodospirillum rubrum, a gram-negative facultative aerobe that belongs to the Rhodospirillaceae family, which can rely on carbon monoxide for its growth and promote the production of PHB in the presence of acetate at the same time [8-12]. Hence, it is a suitable candidate to produce PHB on a CObased feeding.

Even though the CO conversion mechanism is not yet fully understood, genetic and biochemistry studies have demonstrated that the CO conversion of $R$. rubrum is mediated by a membrane protein complex, which orchestrates the biological water-gas shift (WGS) reaction $\left(\mathrm{CO}+\mathrm{H}_{2} \mathrm{O} \rightarrow \mathrm{CO}_{2}+\mathrm{H}_{2}\right)$ [13] (Fig. 1). The oxidation of $\mathrm{CO}$ into $\mathrm{CO}_{2}$ is guaranteed by carbon monoxide dehydrogenase (CODH), a membrane protein that contains a nickel-based binding site and an ironsulphur centre which coordinate $\mathrm{CO}$ and catalyses its 


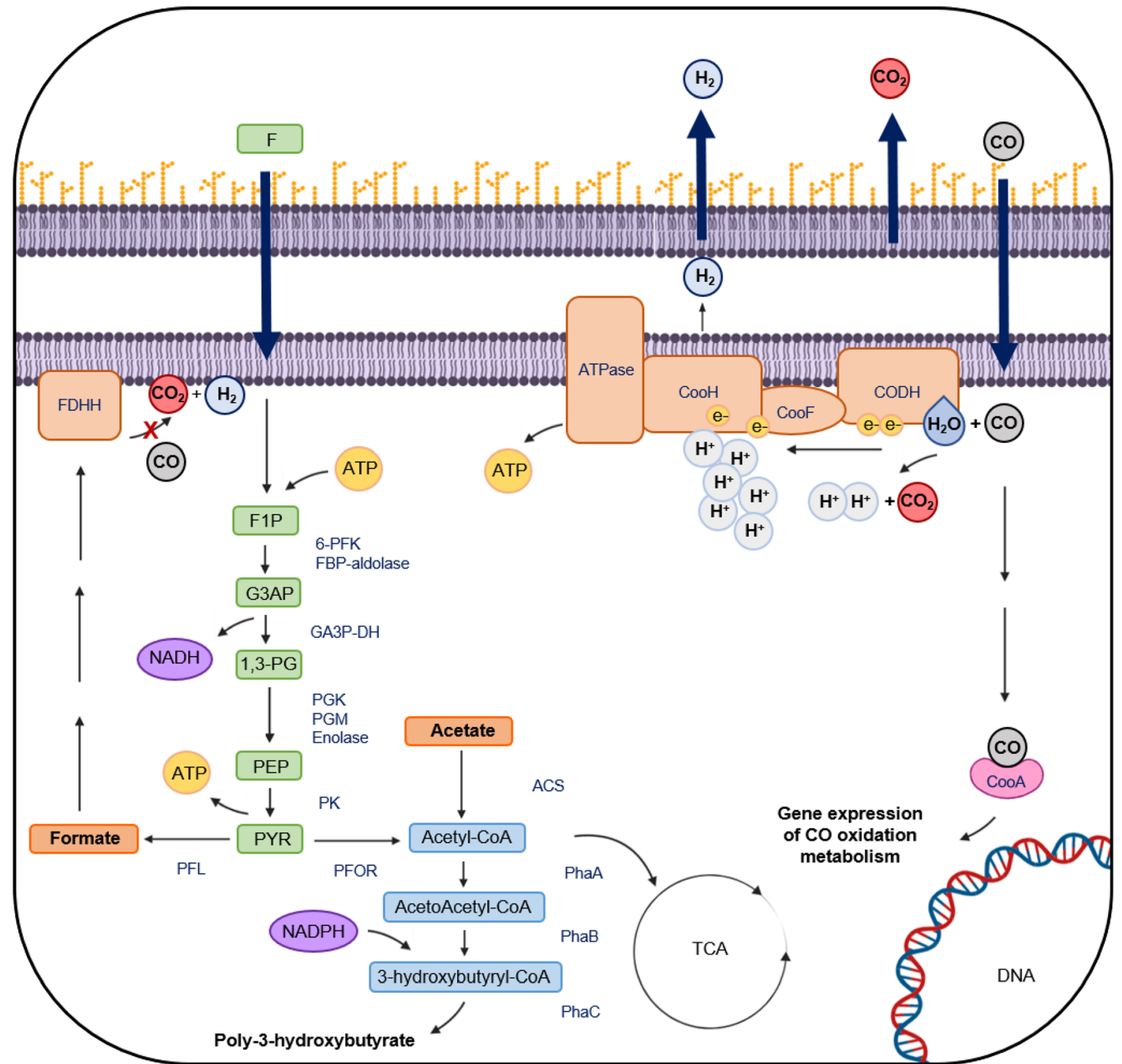

Fig. 1 The principal metabolic pathways of $R$. rubrum on fructose and $\mathrm{CO}$ with acetate. The metabolites and enzymes in the scheme are addressed as follows: F: fructose; F1P: fructose-1-phosphate; 6-PFK: 6phosphofructokinase; FBP-aldolase: fructose-1,6-bisphosphate aldolase; G3AP: glyceraldehyde-3-phosphate; GA3P-DH: glyceraldehyde-3phosphate dehydrogenase; 1,3-PG: 1,3-bisphosphoglycerate; PGK: phosphoglycerate kinase; PGM: phosphoglycerate mutase; PEP: phosphoenolpyruvate; PYR: pyruvate; PFOR: pyruvate synthase; PFL:

oxidation at the expenses of one water molecule, with a consequent release of a couple of protons and a couple of electrons. In this context, the formation of a chemiosmotic gradient across the cell membrane, that is, a transmembrane proton gradient derived from the water-gas-shift reaction, leads to the production of molecular hydrogen and the phosphorylation of ADP molecules [14]. Therefore, it is supposed that a large membrane-bound protein complex composed of $\mathrm{CODH}$, an accessory electron transport protein equipped with an Fe-S centre $(\mathrm{CooF})$, a membrane $\mathrm{CO}$-tolerant $[\mathrm{NiFe}]$-hydrogenase (which is also called CO-linked hydrogenase) and an ATPsynthase can promote (i) proton pumping and (ii) proton pyruvate-formate lyase; FDHH: formate-hydrogen lyase; ACS: acetylCoA synthase; TCA: tricarboxylic acid cycle; PhaA: 3-ketotiolase; PhaB: acetoacetyl-CoA reductase; PhaC: PHB synthase; CODH: carbon monoxide dehydrogenase, $\mathrm{CooF}$ : electron transfer protein; $\mathrm{CooH}$ : $\mathrm{CO}$ induced hydrogenase; ATPase: ATP-synthase; e-: electron; CooA: COdependent transcription factor. The figure was created with BioRender.com

reduction coupled with ATP synthesis activity [15-19]. The cell within this mechanism is able to dissipate electrons in excess and to provide ATP during dark fermentation.

This large membrane-bound complex in R. rubrum is induced by the presence of $\mathrm{CO}$. In fact, it is only once the cells are exposed to carbon monoxide, that a CO-sensor transcriptional activator, $\mathrm{CoOA}$, can bind $\mathrm{CO}$ and turn on the expression of those genes involved in the oxidation of $\mathrm{CO}[15,20-22]$. It has been demonstrated that these transcriptional events present an accumulation profile, with an amount of produced proteins that grows as exposure to carbon monoxide increases [23]. However, even though $\mathrm{CO}$ is the preferred substrate in the 
absence of other carbon sources, an increase in the partial pressure of CO can also determine inhibition events on CO uptake, which results into a slower CO conversion [24, 25].

In similar carboxytrophs species, an acclimation to $\mathrm{CO}$ is a culturing procedure that allows the most efficient cultures to be [26]. For instance, in the acetogen Clostridium ljungdahlii, it has been demonstrated that an adaptation phase, reached by exposing the pre-cultures to $\mathrm{CO}$, could enhance $\mathrm{CO}$ stress tolerance. Moreover, in the same study, it was also demonstrated that the combination of $\mathrm{CO}$ and a reducing sugar could positively affect the accumulation of both the biomass and the end products, such as ethanol or acetate, due to a higher accumulation of energy (e.g., ATP and GTP), and to the reducing equivalents (e.g., NADH) provided by the sugar metabolism [27].

In the studies dedicated to PHB biosynthesis with $\mathrm{CO}$ as the main carbon and energy feedstock, R. rubrum is generally cultivated using syngas as the source of $\mathrm{CO}$ and acetate as the main liquid carbon source. Under these standard culturing conditions, $R$. rubrum presents a linear growth trend because it is mainly limited by $\mathrm{CO}$ mass transfer events from the gas to the liquid phase, with a biomass accumulation yield that is affected by the amount of supplied syngas [10-12]. It has also been demonstrated that the presence of acetate induces the accumulation of PHB [10].

Fructose is a fermentable sugar which can lead to highdensity cultures being achieved in darkness fermentations [28, 29]. However, no information regarding a co-feeding of $\mathrm{CO}$ and sugars has been presented so far. Such a feeding strategy can be identified as mixotrophic fermentation, in order to distinguish it from the standard CO-based fermentation conditions that is carried out on $\mathrm{CO}$ and acetate.

For these reasons, this work has focused on the effects of an adaptation step made with $\mathrm{CO}$ in the wild-type strain of
R. rubrum and has compared them with the contribution of fructose in the presence of carbon monoxide. The strain was exposed to $15 \%$ of CO in $160-\mathrm{mL}$ serum bottles filled to $20 \%$ with the liquid medium for the acclimation and the successive growth cycle. $R$. rubrum was cultured in two consecutive growth cycles, in which the accumulated biomass from the first fermentation run was inoculated into fresh media for a subsequent cultivation cycle. During the experiments, the $\mathrm{CO}$ was restored every $24 \mathrm{~h}$, and the effects of the adaptation on the biomass growth efficiency, the substrate conversion and PHB production were evaluated.

\section{Materials and methods}

\subsection{Bacterial strain and cultivation}

Rhodospirillum rubrum (ATCC 11170) was pre-cultured in a 160 -mL serum bottle which was closed with a rubber stop-cap (Fig. 2). The growth was carried out under darkness in $80 \mathrm{~mL}$ of Rhodospirillum rubrum no-light CO (RRNCO) medium [9, 10], with $15 \mathrm{mM}$ of fructose used as liquid carbon source. The preculture was grown for $48 \mathrm{~h}$ until it reached an optical density of 1.5 at $600 \mathrm{~nm}\left(\mathrm{OD}_{660}\right)$ and it consumed all the fructose present in the medium [12].

The adaptation and culture cycles were run in $160-\mathrm{mL}$ serum bottles filled with $30 \mathrm{~mL}$ of the RNNCO medium and different carbon sources $(3 \mathrm{mM}$ of acetate and 5 or $15 \mathrm{mM}$ of fructose for the mixotrophic condition). The biomass growth started at an initial $\mathrm{OD}_{660}$ of 0.08 . The headspace in the bottle, which corresponded to $130 \mathrm{~mL}$, was filled with $15 \%$ of $\mathrm{CO}$ and $85 \%$ of $\mathrm{N}_{2}$. During biomass growth, the bacteria were fed with the following procedure: the headspace in the bottle was
Fig. 2 The experimental culturing strategy adopted to test a CO-based adaptation in

R. rubrum. Each condition tested is represented by a culturing bottle followed by a description of the carbon source used, where

"Fruct." stands for fructose and "Ac." stands for acetate. The figure was created with

BioRender.com

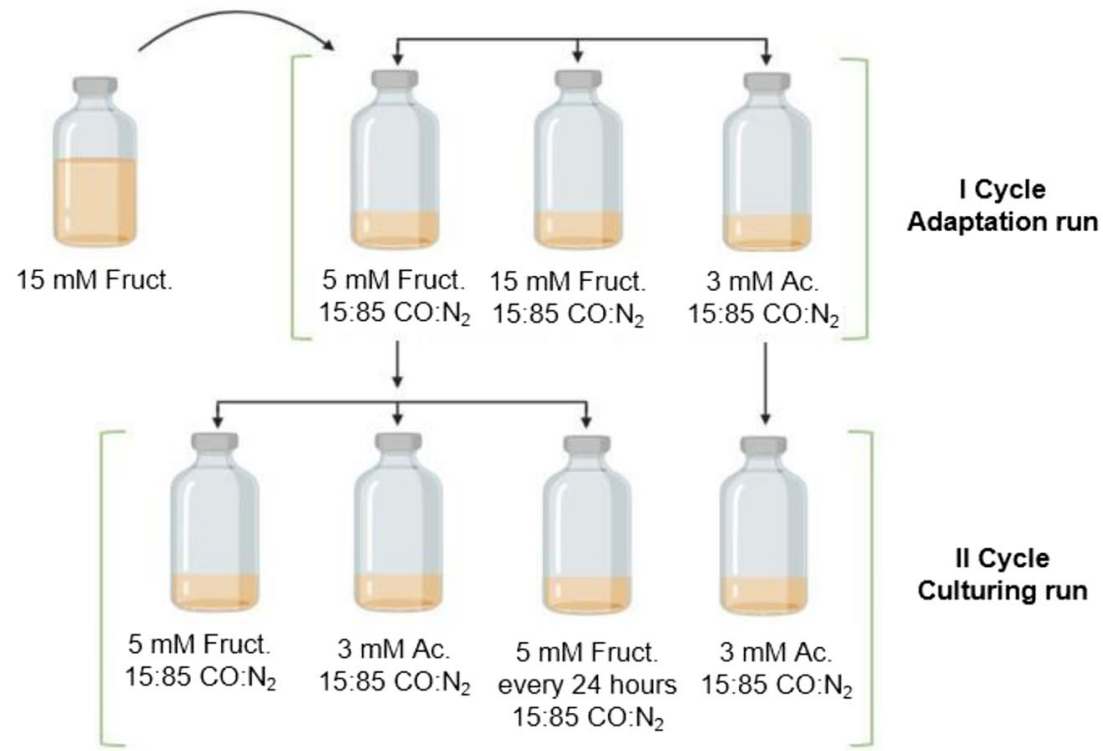


purged for $30 \mathrm{~s}$ using a vacuum pump, washed with $\mathrm{N}_{2}$, purged again for another $30 \mathrm{~s}$ and filled with a fresh aliquot of $\mathrm{CO}$ and $\mathrm{N}_{2}$. This procedure was repeated every $24 \mathrm{~h}$. The experiments were carried out in biological triplicate. All the cultures were conducted at $200 \mathrm{rpm}$ at $30^{\circ} \mathrm{C}$. The experimental strategy consisted in culturing the biomass in a first growth cycle, carried out on $\mathrm{CO}$ and $3 \mathrm{mM}$ of acetate (standard CObased fermentation), or on 5 or $15 \mathrm{mM}$ of fructose (mixotrophic fermentation) for the adaptation cycle. Hence, the cells adapted under the standard CO-based fermentation were seeded in a fresh medium with the same amount of acetate, while the cells grown on $5 \mathrm{mM}$ of fructose were inoculated on a fresh mixotrophic medium with $5 \mathrm{mM}$ of fructose or in an RRNCO medium on $3 \mathrm{mM}$ of acetate. Moreover, the cells that underwent an adaptation cycle on fructose were also inoculated in a mixotrophic medium that was supplied with $5 \mathrm{mM}$ of fructose every $24 \mathrm{~h}$. During the adaptation phase, the growth was stopped before the stationary phase was reached to allow propagation in the second growth cycle.

\subsection{Growth characterisation}

Biomass growth was evaluated measuring the absorbance at $660 \mathrm{~nm}$. Aliquots of $1 \mathrm{~mL}$ were taken from the culture bottles and analysed in a spectrophotometer (Thermo Fisher Scientific), with appropriate dilutions, when necessary. Cell dry weight measurements were determined gravimetrically. Biomass samples were centrifuged at 10,000 rpm for $5 \mathrm{~min}$, washed twice and air-dried at $80{ }^{\circ} \mathrm{C}$ for $12 \mathrm{~h}$ in an oven.

Acetate, fructose and formate were detected by means of HPLC analysis (Shimatzu). After sampling the culture, the medium was filtered using a $0.2-\mu \mathrm{m}$ cellulose nitrate filter and was analysed using an ROA-Organic Acid $\mathrm{H}+(8 \%)$ column (Phenomenex), with an isocratic flux of $0.7 \mathrm{~mL} \mathrm{~min}^{-1}$ of $5 \mathrm{mM}$ of $\mathrm{H}_{2} \mathrm{SO}_{4}$ and a temperature of $50{ }^{\circ} \mathrm{C}$. Acetate, fructose and formic acid were detected after $13.59 \mathrm{~min}, 9.17 \mathrm{~min}$ and $12.3 \mathrm{~min}$ of retention time, respectively. Acetate and fructose were identified by means of a RID detector, while formate was detected using a PDA detector at $206 \mathrm{~nm}$.

\subsection{PHB quantification}

Biomass samples were centrifuged at 10,000 rpm for $5 \mathrm{~min}$, washed twice and dried at $80^{\circ} \mathrm{C}$ for $12 \mathrm{~h}$ in an oven. Once the biomass concentration had been estimated $\left(\mathrm{g} \mathrm{L}^{-1}\right)$, the dry biomasses were hydrolysed with $1 \mathrm{~mL}$ of $96 \% \mathrm{H}_{2} \mathrm{SO}_{4}$ under stirring at $800 \mathrm{rpm}$, in an agitated oil bath at $90^{\circ} \mathrm{C}$ for $1 \mathrm{~h}$. At the end of the reaction, a 1:125 dilution was prepared, and the samples were analysed by means of HPLC (Shimatzu) using an ROA-Organic Acid H+ (8\%) column (Phenomenex), with an isocratic flux of $0.7 \mathrm{~mL} \mathrm{~min}^{-1}$ of $5 \mathrm{mM}^{\circ} \mathrm{H}_{2} \mathrm{SO}_{4}$ and a temperature of $50{ }^{\circ} \mathrm{C}$. The related PHB signal appeared at $210 \mathrm{~nm}$ after $23.09 \mathrm{~min}$ from the injection of the sample, a signal that corresponds to the crotonic acid, the monomer that comes from hydrolysed PHB [30].

\subsection{Gas composition analysis}

In order to perform the analysis of the composition of the gas present in the headspace of the bottle, a gasbag, previously purged and put under vacuum using a vacuum pump, was connected, by a needle, to the serum bottle hosting the $R$. rubrum cultures, and the gas was sampled. The procedure was improved by the presence of an overpressure, which was developed as a result of the performed water gas shift reaction after $24 \mathrm{~h}$ of cultivation. The collected gas was analysed by means of SRA micro-GC, equipped with a Molsive 5A column at a temperature of $100{ }^{\circ} \mathrm{C}$ with argon as the carrier gas (for the quantification of $\mathrm{H}_{2}$ ), and with a PoraPLOT U column at $85{ }^{\circ} \mathrm{C}$, using helium as the carrier gas (for $\mathrm{CO}_{2}$ analysis).

\subsection{Calculations}

The molar growth yield $\left(Y_{\mathrm{mol}}\right)$ was calculated after complete depletion of the consumed substrate. It was calculated on the basis of the work of Schultz [31], considering the total carbon atoms present as the substrate (acetate or fructose), as follows: $\mathrm{mg}$ of collected biomass on mmol of consumed substrate per atom of $\mathrm{C}$ of the substrate.

\section{Results and discussion}

\subsection{Effect of $\mathrm{CO}$ adaptation on biomass accumulation}

R. rubrum was grown under darkness in two successive culture cycles, which are an adaptation run and a cultivation run, respectively (Fig. 3). R. rubrum was fed with $15 \%$ of $\mathrm{CO}$ during both fermentation runs, and its growth trend supported by $\mathrm{CO}$ and acetate was compared with that obtained when $\mathrm{CO}$ and fructose were used as co-substrates. Two different concentrations of fructose, corresponding to 5 and $15 \mathrm{mM}$, were investigated in the adaptation phase to verify its effect on biomass growth. The headspace composition was restored every $24 \mathrm{~h}$ with a fresh mix of $\mathrm{CO}$ and $\mathrm{N}_{2}$ at concentrations of 15 and $85 \%$, respectively. At the end of the first culture cycle (I cycle), the biomass samples were transferred to fresh culture media (II cycle), and the effects of adaptation, as a result of exposure to $\mathrm{CO}$ exposure in the presence of fructose or acetate, were analysed on the growth rate.

During the first growth cycle, the biomass showed an exponential improvement, characterised by a specific growth rate, $\mu_{1}$, of $0.8 \mathrm{~h}^{-1}$ on 5 and $15 \mathrm{mM}$ of fructose, respectively (Fig. 3a). The strain doubled the accumulated biomass, which peaked at an $\mathrm{OD}_{660}$ of 0.62 as a result of the highest tested sugar concentration. A diauxic growth trend was observed, 

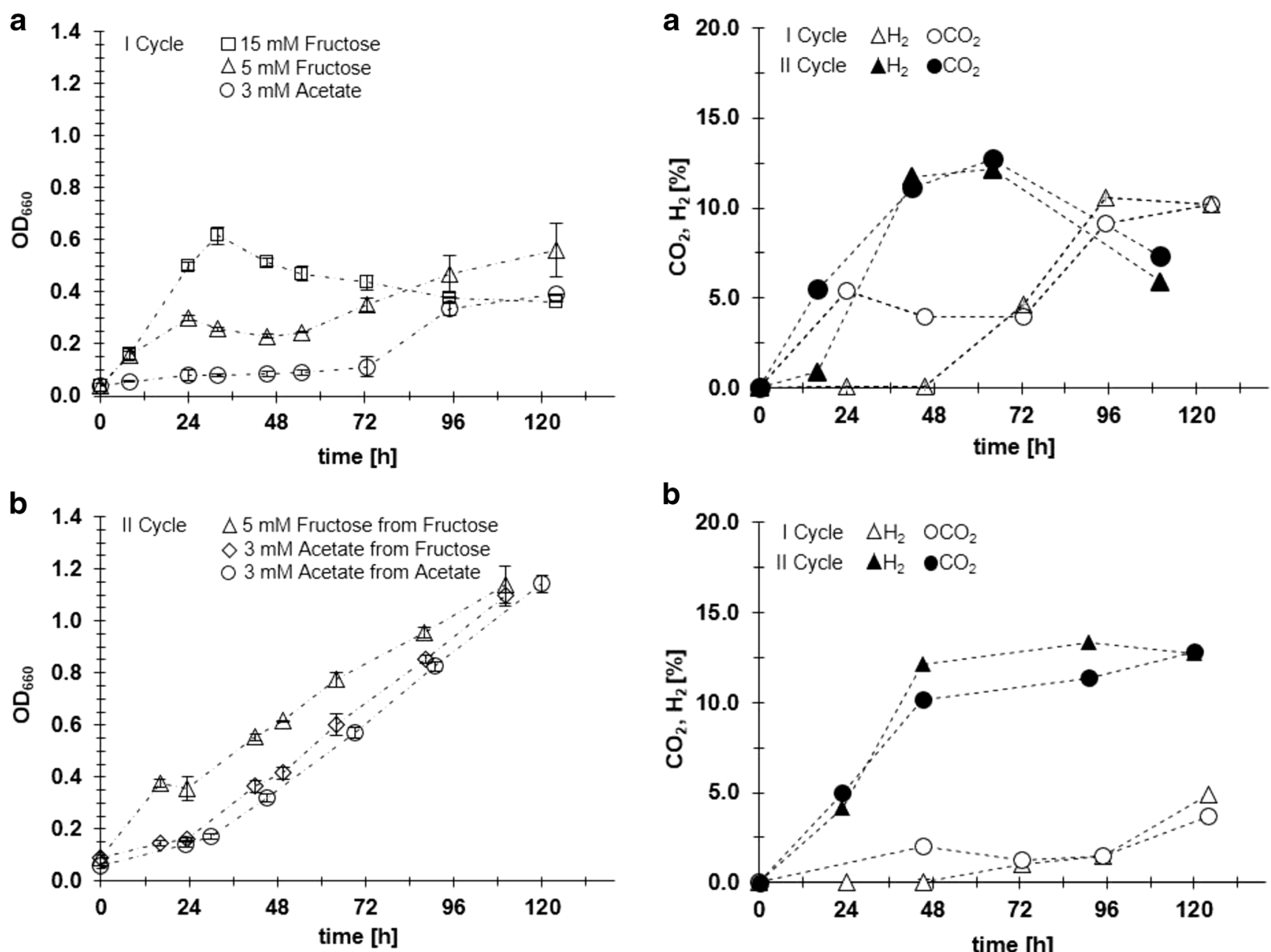

Fig. 3 Adaptation and growth cycles of $R$. rubrum in the presence of $\mathrm{CO}$ under standard CO-based fermentation conditions and mixotrophic growth conditions under darkness. a Adaptation phase of $R$. rubrum on $15 \%$ of CO and $5 \mathrm{mM}$ of fructose $(\Delta), 15 \mathrm{mM}(\square)$ of fructose, or $3 \mathrm{mM}$ of acetate ( $($ ) into the liquid phase. $\mathbf{b}$ Second growth cycle of pre-adapted cultures A. Pre-adapted cultures on $5 \mathrm{mM}$ of fructose were transferred to a fresh liquid medium containing $5 \mathrm{mM}$ of fructose $(\Delta)$ or $3 \mathrm{mM}$ of acetate $(\diamond)$, while pre-adapted cultures on acetate were seeded in a fresh medium containing $3 \mathrm{mM}$ of acetate $(\circ)$. All the experiments were made in biological triplicate

probably due to a metabolic adaptation from sugar-dependent growth to CO-based fermentation, as the evolution of the $\mathrm{CO}_{2} / \mathrm{H}_{2}$ couple from $\mathrm{CO}$ oxidation indicates (Fig. 4). The intermediate lag phase lasted around $24 \mathrm{~h}$ on $5 \mathrm{mM}$ of sugar, after which $R$. rubrum restarted to grow with a $\mu_{2}$ of $0.01 \mathrm{~h}^{-1}$. On the other hand, the diauxic trend was not observed for cultures fed with $15 \mathrm{mM}$ of fructose.

During the standard CO-based fermentation conditions (CO and acetate), $72 \mathrm{~h}$ of adaptation was necessary before the growth phase began at a $\mu_{2}$ of $0.03 \mathrm{~h}^{-1}$. This longer lag phase could be a consequence of the time required for $R$. rubrum to activate the protein complex responsible for the $\mathrm{CO}$ metabolism.

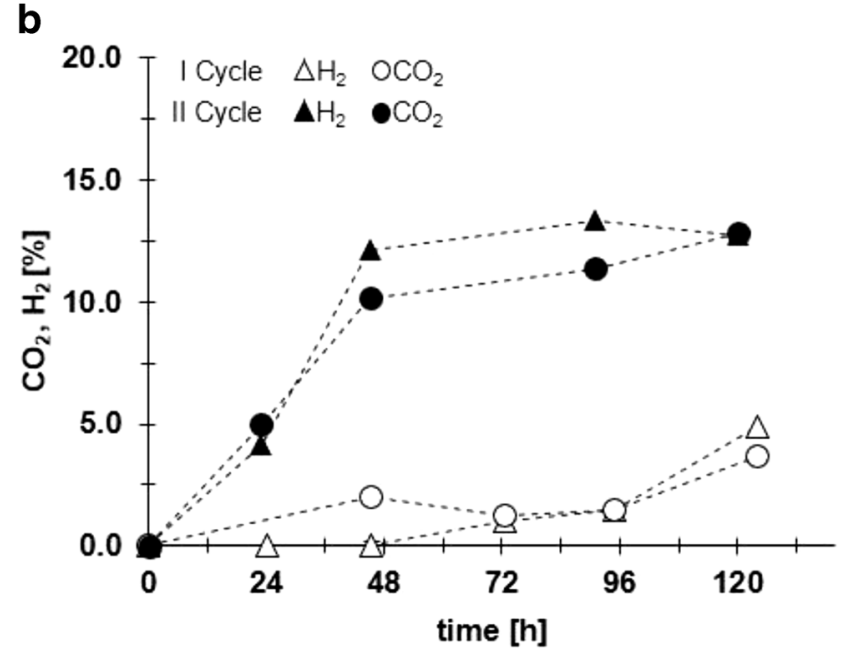

Fig. $4 \mathrm{CO}_{2}$ and $\mathrm{H}_{2}$ production profiles measured in the two successive fermentation cycles. a $\mathrm{CO}_{2}(\mathrm{O}, \bullet)$ and $\mathrm{H}_{2}(\Delta, \boldsymbol{\Delta})$ productions of cultures adapted on $15 \%$ of $\mathrm{CO}$ and $5 \mathrm{mM}$ of fructose. $\mathbf{b ~ C O} \mathrm{CO}_{2}(\mathrm{\circ}, \bullet)$ and $\mathrm{H}_{2}(\Delta, \boldsymbol{\Delta})$ profiles of the standard CO-based fermentation of $15 \% \mathrm{CO}$ and $3 \mathrm{mM}$ of acetate. The adaptation cycle (open symbols) and the second cultivation run (black symbols) are shown in the graph

Both feeding strategies were investigated in the second culture cycle (Fig. 3b). The cultures grown in the presence of fructose were transferred to fresh media supplemented with fructose or acetate, respectively, while the cultures adapted under acetate were moved to a medium with an identical composition. Moreover, since the samples that underwent the adaptation on $15 \mathrm{mM}$ of fructose showed a decreasing biomass trend, they were not propagated.

The first adaptation cycle had two main effects on the second culture run: it diminished the lag phase and promoted biomass growth efficiency. The diauxic growth on $5 \mathrm{mM}$ of fructose showed an intermediate lag phase, which was less than halved with respect to the adaptation cycle, while it diminished by one-third in the case of the standard CO-based fermentation condition. Parallelly, the adaptation to $\mathrm{CO}$ guaranteed a higher biomass yield, and at the end of the observation, the growth efficiency was three-fold higher than the first 
CO-based fermentation, with a maximum biomass accumulation of $0.5 \mathrm{~g} \mathrm{~L}^{-1}$ for both fermentation strategies. Therefore, once $R$. rubrum shifted to a metabolism sustained by CO, no effect of fructose presence was detectable on the biomass trend. This similar biomass concentration reached at the end of both fermentation strategies is evidence of the biomass growth principally being sustained by the presence of $\mathrm{CO}$, once the sugar had been depleted. Indeed, the CO-based feeding lasted 4 days, while fructose-assisted growth lasted less than 1 day.

\subsection{Analysis of the headspace gas composition}

During the first and the second fermentation cycles, the gas phase was restored with $15 \%$ of CO every $24 \mathrm{~h}$. Before the restoration, the amounts of evolved $\mathrm{CO}_{2}$ and $\mathrm{H}_{2}$ were measured under each tested condition. $\mathrm{CO}_{2}$ was the first gas species to be observed in the adaptation phase with $5 \mathrm{mM}$ of fructose (Fig. 4A), as it originates from fructose oxidation, while $\mathrm{H}_{2}$ appeared after the lag phase, thus suggesting a shift to $\mathrm{CO}$-dependent growth. A similar gas profile appeared during the second fermentation cycle in the presence of $5 \mathrm{mM}$ of fructose. However, in this case, the $\mathrm{H}_{2} / \mathrm{CO}_{2}$ couple presented a shift on the time axis. Under the standard CO-based fermentation conditions (Fig. 3B), the $\mathrm{CO}_{2}$ and $\mathrm{H}_{2}$ production profiles followed the same growth trend as the biomass. However, a similar shift was observed on the time axis.

The production profile of $\mathrm{CO}_{2}$ and $\mathrm{H}_{2}$ in 1:1 ratio, measured during standard CO-based fermentation or in the presence of fructose, is evidence of the strain growing under a COlimited condition. Indeed, this is the typical WGS reaction ratio [13]. Even though $R$. rubrum has other ways of producing hydrogen, they were inactivated under the experimental conditions that were applied. R. rubrum can, in fact, produce $\mathrm{H}_{2}$ in another three ways: through the reduction of $\mathrm{N}_{2}$ by nitrogenases, as a product of formate oxidation mediated by a formate-hydrogen lyase complex, and, when it is cultivated with light, by a membrane-bound uptake hydrogenase enzyme (that shows both $\mathrm{H}_{2}$ oxidation and evolution activity). Nevertheless, the presence of ammonium and $\mathrm{CO}$, in the liquid medium and headspace, respectively, ensured the inactivation of both nitrogenases and formate lyase, while the application of darkness prevented the transcription of the $\mathrm{H}_{2}$ uptake hydrogenase [32-36].

\subsection{Growth substrate utilisation and PHB production}

Once the cultures had adapted to the presence of $\mathrm{CO}$ in the first culture cycle, the substrate consumption and product formation were measured in the liquid phase of the second fermentation run by means of HPLC analysis (Fig. 5). The data confirmed that the fructose was depleted in $24 \mathrm{~h}$, in the presence of $5 \mathrm{mM}$ of fructose. The fructose consumption was

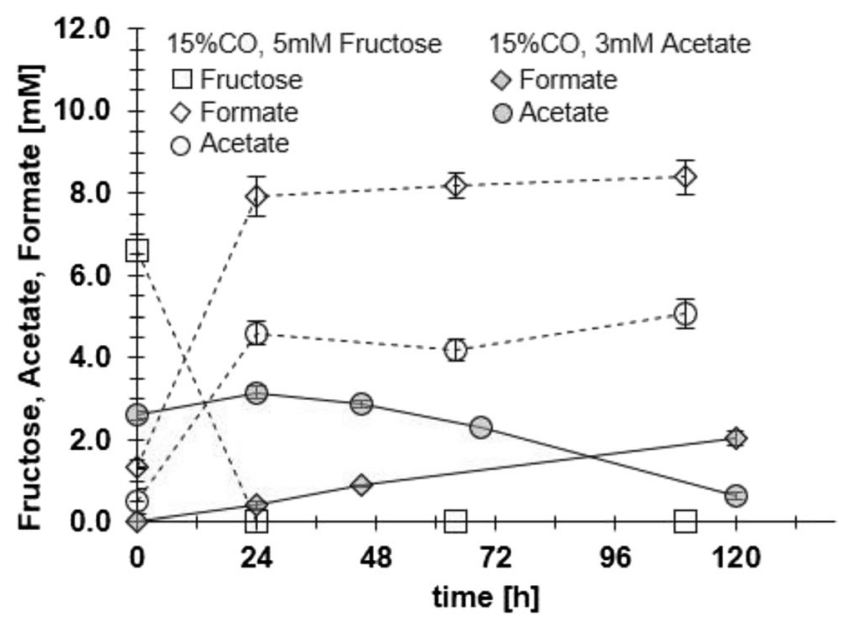

Fig. 5 Fructose and acetate conversion. After the adaptation phase, the variation in the fructose concentration $(\square)$ and the relative production of acetate $(\circ)$ and formate $(\diamond)$ were evaluated by means of HPLC analysis in cultures grown on $15 \%$ of CO and $5 \mathrm{mM}$ of fructose. In the same way, the acetate $(\bullet)$ and formate $(\diamond)$ trends were analysed in samples grown on $15 \%$ of $\mathrm{CO}$ and $3 \mathrm{mM}$ of acetate

followed by a release of $4.6 \pm 0.3 \mathrm{mM}$ of acetate, a value that remained stable throughout the fermentation period. The fructose metabolism in R. rubrum proceeds via the EmbdenMeyerhof-Parnas (EMP) pathway, which, in the absence of oxygen or any other reducing agents, such as dimethyl sulfoxide, is mainly metabolised as formate, succinate, acetate and $\mathrm{CO}_{2}$ [31]. Under this condition, the tricarboxylic acid (TCA) cycle partially operates in reductive mode, causing a contraction of the available reducing equivalents $[31,37,38]$. Accordingly, the consumption of acetate, which occurs when the TCA operates in oxidative mode or when the cell produces PHB, was not observed, while an increase in organic acids was verified, as the formate profile demonstrated.

Formate is the second end-product obtained from the decarboxylation of pyruvate mediated by pyruvate-formate lyase (Fig. 1). Moreover, because of the presence of $\mathrm{CO}$, its further oxidation into $\mathrm{CO}_{2}$ and $\mathrm{H}_{2}$ was prevented $[34,35,39,40]$. Thus, in the presence of $5 \mathrm{mM}$ of fructose, the concentration of formate peaked at a value of $8 \pm 0.4 \mathrm{mM}$ under the mixotrophic condition, while it stayed under $2 \pm 0.2 \mathrm{mM}$ under the standard CO-based fermentation feeding.

In order to confirm whether fructose consumption resulted in an accumulation of formate, a control experiment was carried out in which an adapted $R$. rubrum biomass was cultured with a daily supply of $5 \mathrm{mM}$ of fructose and CO. Figure 6 shows the biomass accumulation, the substrate consumption and the relative acetate and formate evolution. As expected, repetitive fructose-based feeding favoured the accumulation of the biomass, which reached a maximum $\mathrm{OD}_{660}$ of 1.5. Fructose was depleted during biomass accumulation, and $0.58 \pm 0.05 \mathrm{~g} \mathrm{~L}^{-1}$ of biomass, $5.1 \pm 0.1 \mathrm{mM}$ of acetate and $11 \pm 2 \mathrm{mM}$ of formate were achieved, thereby confirming a higher formate accumulation. 


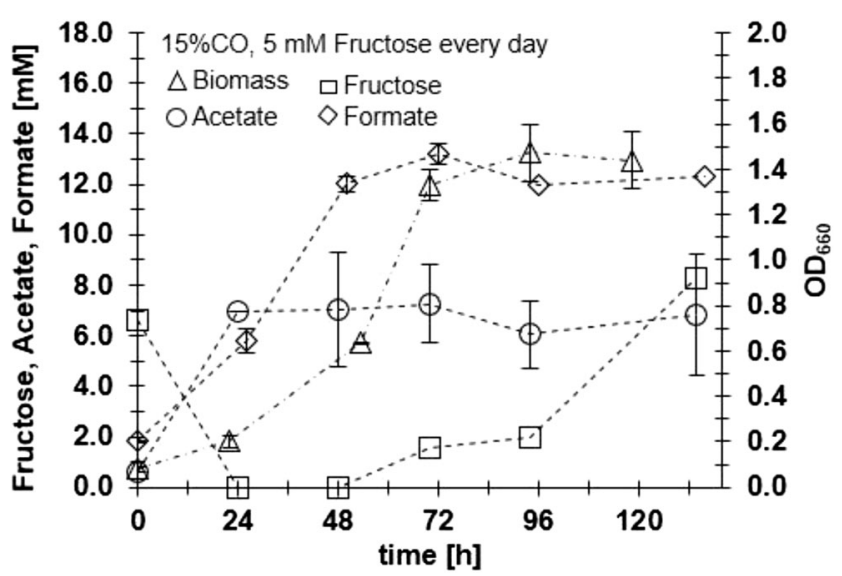

Fig. 6 The effect of organic acid accumulation on repetitive fructosebased feeding. A control culture of adapted R. rubrum on $15 \%$ of $\mathrm{CO}$ was cultured on $15 \%$ of $\mathrm{CO}$ and $5 \mathrm{mM}$ of fructose, which were supplied every $24 \mathrm{~h}$. The biomass $(\Delta)$, acetate $(\circ)$, formate $(\diamond)$ and fructose $(\square)$ were monitored during the fermentation

On the other hand, the acetate was gradually depleted under standard CO-based fermentation conditions (Fig. 5). In this case, the primary electron source for the cell is that of the oxidation of carbon monoxide, and the biomass, therefore, consumed acetate as a building block for biomass and PHB production [10]. A tiny increase in acetate concentration was observed during the first hours of culturing under the standard CO-based fermentation conditions. Such a variation was also observed in similar experiments that are not reported in this work. It could be the result of some products metabolised from the yeast extract, which was present in the medium.

The final amount of produced PHB was measured after the adaptation phase, on the last day in which the fermentation was carried out. As reported in Table 1, a similar amount of PHB was found for the mixotrophic and standard CO-based fermentations, where it peaked at about $8 \%$ with respect to the cellular dry weight. However, the PHB concentration in the control culture, which was exposed to repetitive fructose feeding, showed a PHB accumulation of $3 \%$. In accordance with the trend of formate and acetate, the decrease in PHB accumulation could have been derived from a shift in the electrons and carbon units from the biosynthetic biopolymer pathway to the residual biomass and organic acid production. Hence, the daily supply of reducing sugar could have blocked the restoration of reducing equivalents, caused by a lack of reducing agents, thereby preventing the accumulation of PHB.

On the other hand, the presence of the high acetate concentrations found in the samples fed with $\mathrm{CO}$ and fructose suggests that the small amount of the corresponding PHB was not a consequence of a previous polymer consumption mediated by the biomass itself.

Calculations of the carbon molar growth yield on the liquid carbon sources confirmed that the acetate source resulted in a better investment of carbon resources for the biomass, which showed a yield of $48.33 \mathrm{mg} \mathrm{mmol}^{-1} \mathrm{C}$ as a result of $\mathrm{CO}$ and acetate-based feeding (Table 1). Instead, under mixotrophic conditions, the same index corresponded to 12 and $4 \mathrm{mg} \mathrm{mmol}^{-1} \mathrm{C} \mathrm{mol}^{-1}$, respectively, for single and repetitive fructose supplies. Similar values were also reported in the work of Schultz, where R. rubrum was cultured in an anaerobic environment with a fructose supply [31].

The $\mathrm{pH}$ was also measured for each tested condition. In the case of the standard CO-based fermentation condition, and in the presence of $5 \mathrm{mM}$ of fructose, its value was almost stable at around 7.5 throughout the entire fermentation. In samples in which fructose was added every $24 \mathrm{~h}$, it instead dropped day by day, passing from 7.5 to 4.9 , because of the higher amount of formate in the media.
Table 1 Growth rate, maximal accumulated biomass, molar growth yield and the percentage of PHB collected for the standard CO-based fermentation and mixotrophic cultures, respectively. Data were collected during the adaptation (I cycle) and during the second culture run (II cycle). In the graph, $\mu_{1}$ and $\mu_{2}$ indicate the specific biomass growth observed during the adaptation and during the second fermentation cycle, respectively

\begin{tabular}{|c|c|c|c|c|c|c|c|}
\hline & $\mathrm{CO}$ & Feeding & $\mu_{1}\left(\mathrm{~h}^{-1}\right)$ & $\mu_{2}\left(\mathrm{~h}^{-1}\right)$ & $\begin{array}{l}\text { Maximal } \\
\text { biomass }\left(\mathrm{g} \mathrm{L}^{-1}\right)\end{array}$ & $\begin{array}{l}\text { Molar growth yield } \\
\left(\mathrm{mg} \mathrm{mol}^{-1}\right)^{\mathrm{a}}\end{array}$ & $\operatorname{PHB}(\%)$ \\
\hline Anaerobic, pure $\mathrm{N}_{2}$ & - & $5 \mathrm{mM}$ fructose & 0.08 & & 0.13 & 4.3 & l \\
\hline Adaptation & + & $5 \mathrm{mM}$ fructose & 0.08 & 0.01 & $0.24 \pm 0.06$ & & n.d. \\
\hline Adaptation & & $15 \mathrm{mM}$ fructose & 0.08 & 1 & $0.23 \pm 0.01$ & $7.6^{\mathrm{b}}$ & n.d. \\
\hline Adaptation & + & $3 \mathrm{mM}$ acetate & 0 & 0.03 & $0.15 \pm 0.08$ & & n.d. \\
\hline Culture & + & $5 \mathrm{mM}$ fructose & 0.06 & 0.01 & $0.37 \pm 0.05$ & 12 & $7 \%$ \\
\hline Culture & + & $5 \mathrm{mM}$ fructose (every $24 \mathrm{~h}$ ) & 0.04 & l & $0.58 \pm 0.05$ & 4 & $3 \%$ \\
\hline Culture & + & $3 \mathrm{mM}$ acetate & 0.03 & / & $0.45 \pm 0.01$ & 48.3 & $8 \%$ \\
\hline
\end{tabular}

${ }^{a}$ The molar growth yield was calculated as reported in the work of Schultz [27]

${ }^{\mathrm{b}}$ This value was calculated taking into account the highest registered biomass concentration 


\subsection{The $\mathrm{CO}$ adaptation mechanism}

The substrate adaptation on $15 \%$ of carbon monoxide resulted in a decrease in the time necessary to metabolise $\mathrm{CO}$, as reported in Fig. 2, and in turn caused a reduction in the lag phase. In the presence of carbon monoxide, the production of energy relies on the formation of a chemiosmotic $\mathrm{H}^{+}$gradient across the membrane [19]. As previously reported in the literature, the $\mathrm{CODH}$ complex shows a rapid response to $\mathrm{CO}$, once this molecule has entered the cells [23]. However, its transcription depends on the CooA transcriptional factor, which is activated by $\mathrm{CO}$ [41].

The results have demonstrated that the first exposure to $\mathrm{CO}$ determined the generation of a metabolically active population ready to take advantage of $\mathrm{CO}$ in the successive cultures, which may have relied on a higher availability of the $\mathrm{CO}$ oxidation protein complexes from the adapted cells. As anticipated, the $\mathrm{CO}$ oxidation complex is arranged in order to connect the $\mathrm{CODH}$ with a membrane ATPase, and efficiently ensure the synthesis of ATP, which is the only energy source of CO-based feeding $[18,19]$. The possibility of promptly taking advantage of $\mathrm{CO}$, after the first exposure to $\mathrm{CO}$, could render the ATP more available to the cells, thus resulting in a reduced lag-phase. Hence, $\mathrm{H}_{2}$ evolved earlier in the adapted cultures during the second culturing round, thus pointing out a parallel ATP production.

In the same way, in another carboxytrophs species, that is, Citrobacter amalonaticus Y19, the over-expression of the transcriptional factor CooA was shown to lead to an improvement of the whole $\mathrm{CO}$ oxidation protein complexes, as demonstrated by the increased activities of $\mathrm{CODH}$ and $\mathrm{CO}-$ tolerant hydrogenase [42].

In our experiments, a similar effect of the influence of the energy balance on the growth was recognised in those cultures supplied with $5 \mathrm{mM}$ of fructose, which did not show a detectable lag phase maybe because of the higher ATP/NAD(P)H supply that was ensured by the sugar. As proof of this effect, it is necessary to note that such behaviour has also been identified in Thermoanaerobacter kivui, which, once adapted to carbon monoxide, presented a rise in the growth efficiency, as could be seen from the measured higher activity of $\mathrm{CODH}$; moreover, CO-resistant hydrogenase improved the production of measured ATP [43].

\section{Conclusion}

The application of exhaust fumes produced by industrial activities as a feed for microbial fermentation is an example of how different production processes can interact with each other in respect of a circular economy strategy. In this scenario, this study has focused on the effects that an adaptation phase on $\mathrm{CO}$ can have on $R$. rubrum.
The exposure to $\mathrm{CO}$ determined the generation of a metabolically active biomass, which was promptly able to activate the oxidation of $\mathrm{CO}$ during the subsequent cultivation run. The adaptation phase could act in favour of the biomass energy balance derived from the $\mathrm{CO}$ metabolism and, consequently, reduce the lag phase and improve the accumulation of biomass.

Moreover, the supply of fructose showed positive effects during the first steps of $R$. rubrum growth, even in the presence of carbon monoxide. However, unlike what was observed for Clostridium ljungdahlii, in which ethanol production increased by $20 \%$ after an adaptation made with fructose and $\mathrm{CO}$, the addition of a reducing sugar did not lead to any improvement in PHB accumulation.

The PHB accumulation capacity decreased as a result of repeated fructose feeding, and the carbon units could be preferentially spent on the biosynthesis of residual biomass or were released as either organic acids and $\mathrm{CO}_{2}$. In this way, it has been demonstrated that the feeding of a reducing sugar, in combination with $\mathrm{CO}$, is useful to trigger the biomass growth. However, once the cells have adapted to the presence of $\mathrm{CO}$, it becomes the preferred electron donor for the PHB biosynthesis and biomass growth.

Acknowledgements The author would like to thank Dr. Auxiliadora Prieto of the Centro de Investigaciones Bológicas of the National Research Council (CSIC-CIB) (Madrid, Spain) and her Polymer Biotechnology group, who kindly provided the bacteria strain used in this work. This work has been funded by the Horizon 2020 EU Framework Programme: CELBICON project, Grant agreement number: 679050.

Funding information Open access funding provided by Politecnico di Torino within the CRUI-CARE Agreement. This work has been funded by the Horizon 2020 EU Framework Programme: CELBICON project, Grant agreement number: 679050.

Data availability Not applicable.

\section{Compliance with ethical standards}

Conflict of interest The authors declare that they have no conflict of interest.

Code availability Not applicable.

Open Access This article is licensed under a Creative Commons Attribution 4.0 International License, which permits use, sharing, adaptation, distribution and reproduction in any medium or format, as long as you give appropriate credit to the original author(s) and the source, provide a link to the Creative Commons licence, and indicate if changes were made. The images or other third party material in this article are included in the article's Creative Commons licence, unless indicated otherwise in a credit line to the material. If material is not included in the article's Creative Commons licence and your intended use is not permitted by statutory regulation or exceeds the permitted use, you will need to obtain permission directly from the copyright holder. To view a copy of this licence, visit http://creativecommons.org/licenses/by/4.0/. 


\section{References}

1. Zhong Q, Huang Y, Shen H, Chen Y, Chen H, Huang T, Zeng EY, Tao S (2017) Global estimates of carbon monoxide emissions from 1960 to 2013. Environ Sci Pollut Res 24:864-873. https://doi.org/ 10.1007/s11356-016-7896-2

2. Zhu Q (2019) Developments on $\mathrm{CO}_{2}$-utilization technologies. Clean Energy 3:85-100. https://doi.org/10.1093/ce/zkz008

3. Almeida Benalcázar E, Noorman H, Maciel Filho R, Posada JA (2020) Modeling ethanol production through gas fermentation: a biothermodynamics and mass transfer-based hybrid model for microbial growth in a large-scale bubble column bioreactor. Biotechnol Biofuels 13:1-19. https://doi.org/10.1186/s13068-02001695-y

4. Bátori V, Åkesson D, Zamani A, Taherzadeh MJ, Sárvári Horváth I (2018) Anaerobic degradation of bioplastics: a review. Waste Manag 80:406-413. https://doi.org/10.1016/j.wasman.2018.09. 040

5. Jambeck JR, Geyer R, Wilcox C et al (2015) Plastic waste inputs from land into the ocean. Science (80- ) 347:768-771

6. Georgios K, Silva A, Furtado S (2016) Applications of green composite materials. Biodegrad Green Compos 312-337. https://doi. org/10.1002/9781118911068.ch10

7. Oliveira CS, Silva C, Carvalho GRMA (2016) Strategies for efficiently selecting PHA producing mixed microbial cultures using complex feedstocks: feast and famine regime and uncoupled carbon and nitrogen availabilities. New Biotechnol 37:69-79. https://doi. org/10.1016/j.nbt.2016.10.008

8. Munk AC, Copeland A, Lucas S, Lapidus A, del Rio TG, Barry K, Detter JC, Hammon N, Israni S, Pitluck S, Brettin T, Bruce D, Han C, Tapia R, Gilna P, Schmutz J, Larimer F, Land M, Kyrpides NC, Mavromatis K, Richardson P, Rohde M, Göker M, Klenk HP, Zhang Y, Roberts GP, Reslewic S, Schwartz DC (2011) Complete genome sequence of Rhodospirillum rubrum type strain (S1). Stand Genomic Sci 4:293-302. https://doi.org/10.4056/sigs. 1804360

9. Kerby RL, Ludden PW, Roberts GP (1995) Carbon monoxidedependent growth of Rhodospirillum rubrum. J Bacteriol 177: 2241-2244. https://doi.org/10.1128/JB.177.8.2241-2244.1995

10. Revelles O, Tarazona N, García JL, Prieto MA (2016) Carbon roadmap from syngas to polyhydroxyalkanoates in Rhodospirillum rubrum. Environ Microbiol 18:708-720. https:// doi.org/10.1111/1462-2920.13087

11. Do YS, Smeenk J, Broer KM, Kisting CJ, Brown R, Heindel TJ, Bobik TA, DiSpirito AA (2007) Growth of Rhodospirillum rubrum on synthesis gas: conversion of $\mathrm{CO}$ to $\mathrm{H}_{2}$ and poly-betahydroxyalkanoate. Biotechnol Bioeng 97:279-286. https://doi.org/ 10.1002/bit.21226

12. Karmann S, Panke S, Zinn M (2019) Fed-batch cultivations of Rhodospirillum rubrum under multiple nutrient-limited growth conditions on syngas as a novel option to produce poly(3hydroxybutyrate) (PHB). Front Bioeng Biotechnol 7:1-11. https:// doi.org/10.3389/fbioe.2019.00059

13. Dadak A, Aghbashlo M, Tabatabaei M, Najafpour G, Younesi H (2016) Sustainability assessment of photobiological hydrogen production using anaerobic bacteria (Rhodospirillum rubrum) via exergy concept: effect of substrate concentrations. Environ Prog Sustain Energy 35:1166-1176. https://doi.org/10.1002/ep.12296

14. Maness PC, Huang J, Smolinski S, Tek V, Vanzin G (2005) Energy generation from the $\mathrm{CO}$ oxidation-hydrogen production pathway in Rubrivivax gelatinosus. Appl Environ Microbiol 71:2870-2874. https://doi.org/10.1128/AEM.71.6.2870-2874.2005

15. Fox JD, Kerby RL, Roberts GP, Ludden PW (1996) Characterization of the $\mathrm{CO}$-induced, CO-tolerant hydrogenase from Rhodospirillum rubrum and the gene encoding the large subunit of the enzyme. J Bacteriol 178:1515-1524

16. Ensign SA, Ludden PW (1991) Characterization of the CO oxidation $/ \mathrm{H}_{2}$ evolution system of Rhodospirillum rubrum: role of a 22$\mathrm{kDa}$ iron-sulfur protein in mediating electron transfer between carbon monoxide dehydrogenase and hydrogenase. J Biol Chem 266: 18395-18403

17. Drennan CL, Heo J, Sintchak MD, Schreiter E, Ludden PW (2001) Life on carbon monoxide: X-ray structure of Rhodospirillum rubrum Ni-Fe-S carbon monoxide dehydrogenase. Proc Natl Acad Sci U S A 98:11973-11978. https://doi.org/10.1073/pnas. 211429998

18. Maness PC, Smolinski S, Dillon AC, Heben MJ, Weaver PF (2002) Characterization of the oxygen tolerance of a hydrogenase linked to a carbon monoxide oxidation pathway in Rubrivivax gelatinosus. Appl Environ Microbiol 68:2633-2636. https://doi.org/10.1128/ AEM.68.6.2633-2636.2002

19. Singer SW, Hirst MB, Ludden PW (2006) CO-dependent $\mathrm{H}_{2}$ evolution by Rhodospirillum rubrum: role of $\mathrm{CODH}: \mathrm{CooF}$ complex. Biochim Biophys Acta Bioenerg 1757:1582-1591. https://doi.org/ 10.1016/j.bbabio.2006.10.003

20. Wawrousek K, Noble S, Korlach J, Chen J, Eckert C, Yu J, Maness PC (2014) Genome annotation provides insight into carbon monoxide and hydrogen metabolism in Rubrivivax gelatinosus. PLoS One 9:1-18. https://doi.org/10.1371/journal.pone.0114551

21. Shelver D, Kerby RL, He Y, Roberts GP (1995) Carbon monoxideinduced activation of gene expression in Rhodospirillum rubrum requires the product of $\mathrm{cooA}$, a member of the cyclic AMP receptor protein family of transcriptional regulators. J Bacteriol 177:21572163. https://doi.org/10.1128/jb.177.8.2157-2163.1995

22. Roberts GP, Youn H, Kerby RL (2004) CO-sensing mechanisms. Microbiol Mol Biol Rev 68:453-473. https://doi.org/10.1128/ MMBR.68.3.453

23. Bonam D, Lehman L, Roberts GP, Ludden PW (1989) Regulation of carbon monoxide dehydrogenase and hydrogenase in Rhodospirillum rubrum: effects of $\mathrm{CO}$ and oxygen on synthesis and activity. J Bacteriol 171:3102-3107. https://doi.org/10.1128/ jb.171.6.3102-3107.1989

24. Klasson KT, Gupta A, Clausen EC, Gaddy JL (1993) Evaluation of mass-transfer and kinetic parameters for Rhodospirillum rubrum in a continuous stirred tank reactor. Appl Biochem Biotechnol 39: 549-557

25. Cowger JP, Klasson KT, Ackerson MD, Clausen E, Caddy JL (1992) Mass-transfer and kinetic aspects in continuous bioreactors using Rhodospirillum rubrum. Appl Biochem Biotechnol 34-35: 613-624. https://doi.org/10.1007/BF02920582

26. Esquivel-Elizondo S, Delgado AG, Krajmalnik-Brown R (2017) Evolution of microbial communities growing with carbon monoxide, hydrogen, and carbon dioxide. FEMS Microbiol Ecol 93:1-12. https://doi.org/10.1093/femsec/fix076

27. Tirado-Acevedo OL, Cotter J. S., Chinn M. M., Grunden A (2011) Influence of carbon source pre-adaptation on Clostridium ljungdahlii growth and product formation. J Bioprocess Biotech 01: https://doi.org/10.4172/2155-9821.s2-001

28. Ghosh R, Hardmeyer A, Thoenen I, Bachofen R (1994) Optimization of the Sistrom culture medium for large-scale batch cultivation of Rhodospirillum rubrum under semiaerobic conditions with maximal yield of photosynthetic membranes. Appl Environ Microbiol 60:1698-1700

29. Zeiger L, Grammel H (2010) Model-based high cell density cultivation of Rhodospirillum rubrum under respiratory dark conditions. Biotechnol Bioeng 105:729-739. https://doi.org/10.1002/bit.22589

30. Braunegg G (1978) A rapid gas chromatographic method for the determination of poly- $\beta$-hydroxybutyric acid in microbial biomass. Eur J Appl Microbiol Biotechnol 7:29-37 
31. Schultz JE, Weaver PF (1982) Fermentation and anaerobic respiration by Rhodospirillum rubrum and Rhodopseudomonas capsulata. J Bacteriol 149:181-190. https://doi.org/10.1128/jb.149.1.181-190. 1982

32. Kim EJ, Lee MK, Kim MS, Lee JK (2008) Molecular hydrogen production by nitrogenase of Rhodobacter sphaeroides and by Feonly hydrogenase of Rhodospirillum rubrum. Int J Hydrog Energy 33:1516-1521. https://doi.org/10.1016/j.ijhydene.2007.09.044

33. Lehman LJ, Roberts GP (1991) Identification of an alternative nitrogenase system in Rhodospirillum rubrum. J Bacteriol 173:57055711. https://doi.org/10.1128/jb.173.18.5705-5711.1991

34. Voelskow H, Schön G (1980) $\mathrm{H}_{2}$ production of Rhodospirillum rubrum during adaptation to anaerobic dark conditions $\mathrm{H}$. Voelskow \& G Schön 125:245-249. https://doi.org/10.1007/ BF00446884

35. McDowall JS, Murphy BJ, Haumann M et al (2014) Bacterial formate hydrogenlyase complex. Proc Natl Acad Sci U S A 111: E3948-E3956. https://doi.org/10.1073/pnas.1407927111

36. Maness PC, Weaver PF (2001) Evidence for three distinct hydrogenase activities in Rhodospirillum rubrum. Appl Microbiol Biotechnol 57:751-756. https://doi.org/10.1007/s00253-0010828-0

37. Carius L, Carius AB, McIntosh M, Grammel H (2013) Quorum sensing influences growth and photosynthetic membrane production in high-cell-density cultivations of Rhodospirillum rubrum. BMC Microbiol 13:189. https://doi.org/10.1186/1471-2180-13189
38. Hädicke O, Grammel H, Klamt S (2011) Metabolic network modeling of redox balancing and biohydrogen production in purple nonsulfur bacteria. BMC Syst Biol 5:150. https://doi.org/10.1186/ 1752-0509-5-150

39. Schon G, Voelskow H (1976) Pyruvate fermentation in Rhodospirillum rubrum and after transfer from aerobic to anaerobic conditions in the dark. 107:87-92. https://doi.org/10.1007/ BF00427872

40. Jungermann K, Schön G (1974) Pyruvate formate lyase in Rhodospirillum rubrum Ha adapted to anaerobic dark conditions. Arch Microbiol 99:109-116. https://doi.org/10.1007/BF00696227

41. Roberts GP, Kerby RL, Youn H, Conrad M (2005) CooA, a paradigm for gas sensing regulatory proteins. J Inorg Biochem 99:280 292. https://doi.org/10.1016/j.jinorgbio.2004.10.032

42. Ainala SK, Seol E, Sekar BS, Park S (2014) Improvement of carbon monoxide-dependent hydrogen production activity in Citrobacter amalonaticus $\mathrm{Y} 19$ by over-expressing the CO-sensing transcriptional activator, CooA. Int J Hydrog Energy 39:10417-10425. https://doi.org/10.1016/j.ijhydene.2014.04.148

43. Weghoff MC, Müller V (2016) CO metabolism in the thermophilic acetogen Thermoanaerobacter kivui. Appl Environ Microbiol 82: 2312-2319. https://doi.org/10.1128/AEM.00122-16

Publisher's Note Springer Nature remains neutral with regard to jurisdictional claims in published maps and institutional affiliations. 